\title{
Water Transfer by Tangential Line Method - A Suggestion to Solve All Kinds of Water Related Problems in the World
}

\author{
T. Bharathi Mohan ${ }^{1}$ \\ ${ }^{1}$ Kumarapuri Colony, Bharathipuram, Dharmapuri - 636705 Tamil Nadu, India \\ Correspondence: T. Bharathi Mohan, 32-a, kumarapuri colony, bharathipuram, dharmapuri - 636705 tamil nadu, \\ India. E-mail: tbharathimohan62@gmail.com
}

Received: February 18, 2017

Accepted: March 18, 2017

Online Published: July 20, 2017

doi:10.5539/esr.v6n2p149

URL: https://doi.org/10.5539/esr.v6n2p149

\begin{abstract}
I would like to extend my idea in this article to over come the first and foremost need of lives which till now exists in the planet earth and no authenticated news of availability in any other planet -WATER and its Conservation.

From the water rich sources, we can transfer the water from one place to another without using electricity. This is possible by fixing the pipe lines parallel to the tangential line of the Earth Circle.
\end{abstract}

Keywords: water transfer, water rich sources

\section{Introduction}

When we see at the beach a ship sailing from far to us. We will

first see its mast.

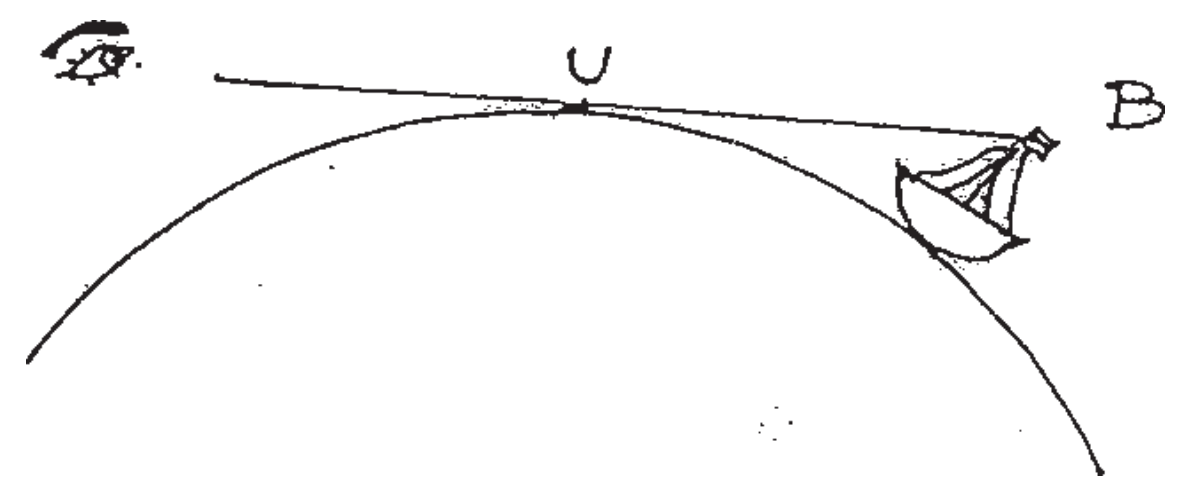

Example 1. U B - Tangential line

Let us Imagine the line UB is a pipe line, ' $U^{\prime}=$ uninterrupted water source, $B=$ water Tank o f the ship.

Then there is no doubt that the water will flow from $U$ to B freely and fill the tank in the ship without taking any extra effort' like pumping or any other from of using electricity etc.,

By using the tangential line formula of a circle, we can transfer the water from one place to other without using electricity.

Example: 1 


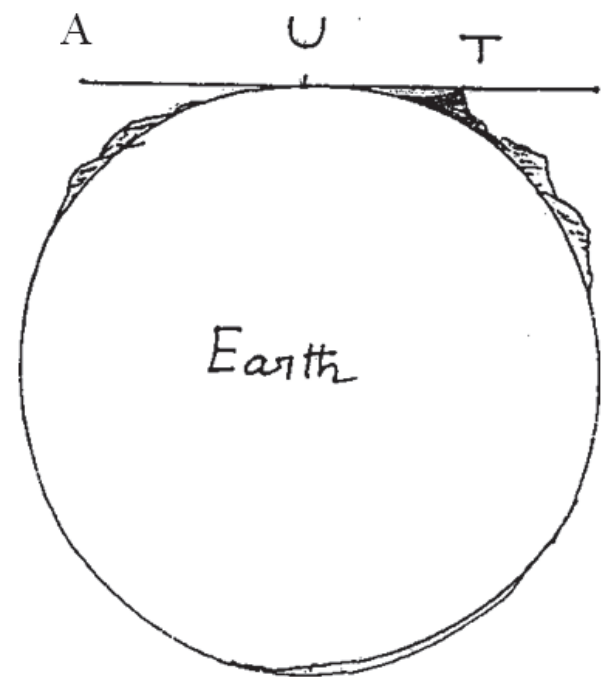

Example 2.

If we are prepare to convert the Imaginary line A $\mathrm{T}$ into pipe line, (ie, from $\mathrm{U}$ to $\mathrm{T}$ ) there is no doubt that the water will flow from a plain land to the top of the high level area. In other words, water will flow freely up to the maximum distance of the Earth's Gravity allows.

U: Uninterrupted and rich water source. T: High level areas

\section{Example:2}

Let us Imagine, suppose the starting point of a pipe line (A) is fixed in an uninterrupted - rich water Source like river, waterfall, Glacier etc:, and the other end is placed at a lake or pond (B).

We can fix many number of pipe lines at B (as shown in the figure) to transfer the excess water to positions C,D,E,F and so on.

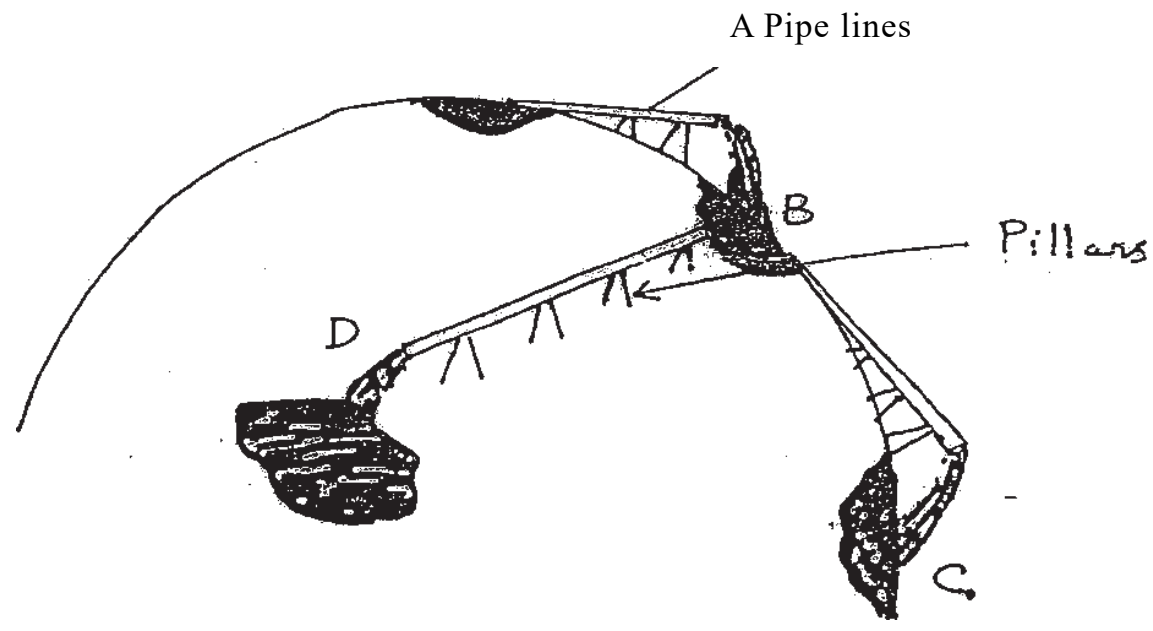

Example 3.

For Example, when we see a ship from a beach, we will see its mast first because of curved shape of the Earth. Let us imagine the place where we are seeing the ship is an uninterrupted water source and the mast of the ship is a water tank. And if a straight pipe line is fixed from that place to the mast of the ship, then there is no doubt that the water will flow freely and fill the tank in the top of the ship without taking any extra effort like pumping by using electricity etc.,

This imaginary pipe line which is horizontal to the Earth's curve is called tangential line [Here we may 
remember the tangential line of a circle]. If we fix such pipe lines (By using pillars) from water rich sources like River, Water falls etc., to the places like ponds, lakes and water needy areas - in chain - we may transfer water within a short span of time. And we may even transfer water from the plain land to the top of the high level areas. In other words, water will flow freely through the pipe lines up to the maximum distance to which the Earth's Gravity allows. The height of each pillar will vary (from smaller one and gradual increase in height corresponding to the curvature of the ground surface and according to the distance through which the pipes are laid) while constructing pillars from water source to the place where water is required. It is to be noted that the pipes should be fixed horizontally so that it remains equal to the tangential line of the earth to ensure free flow of water throughout the pipeline.

\section{Flood \& Pipe Line System}

\section{[A] Usage of Pipe Line System When Floods Occur on Rivers}

Floods occur on rivers mainly due to melting of snow and heavy rainfall. Because of flood, rivers overflow their banks. The overflowed excess water can be transferred by the pipe line system. The pipes are to be fixed on both sides of the river like the $\mathrm{n}$ the skeleton system of the fish as in figure. The pipes are to be fixed at the banks at the danger level mark of the river. Hence during flood, water will automatically get transferred through the pre-fixed pipe lines to the far away ponds or lakes connected by the Pipes which can be utilized by the needy. The transferred water will again get transferred by similar process in chain to other ponds / lakes / water storage system when the previous one is overflowed.

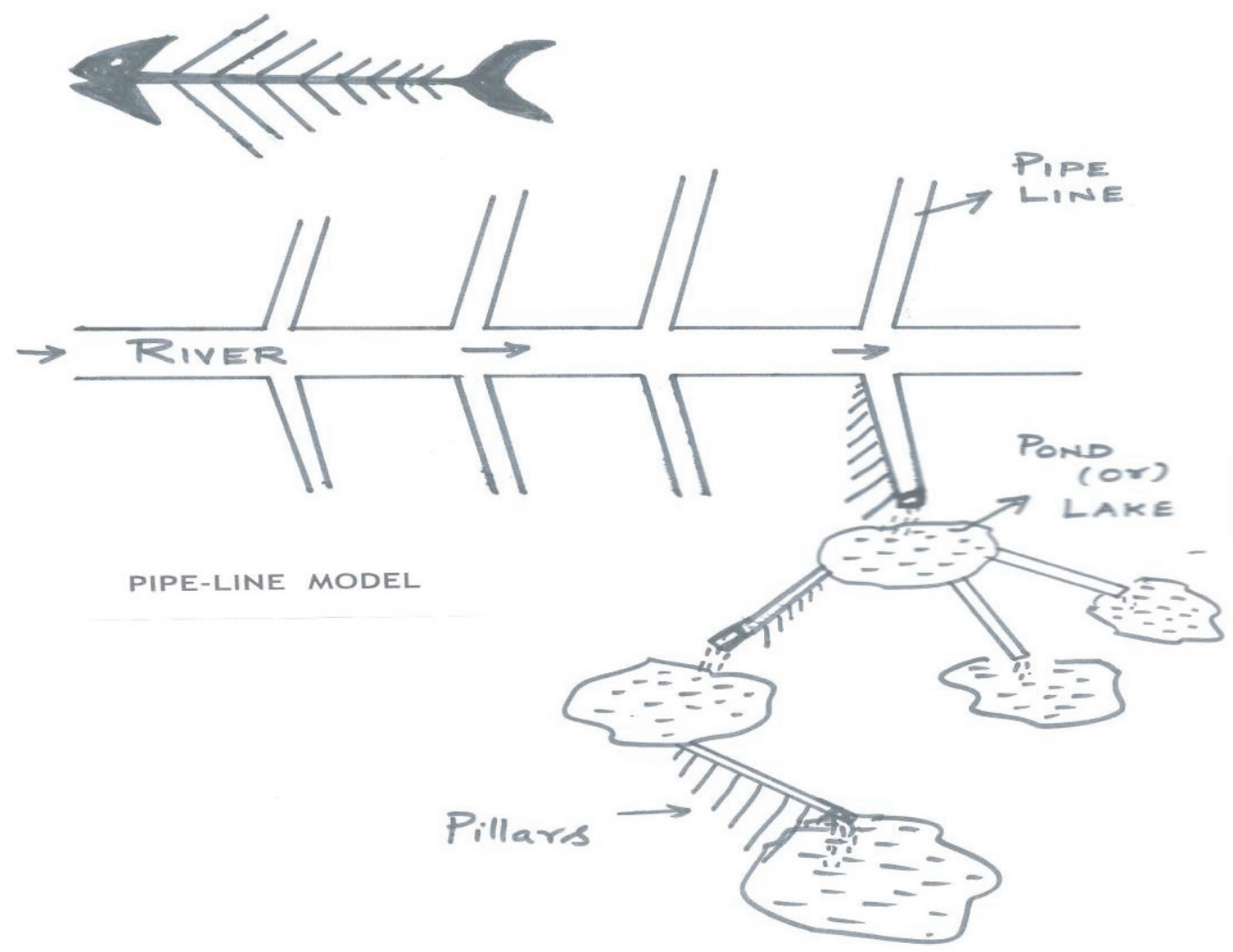

By this method, in each stage, only the excess water is transferred from one place to another. Hence, the water sharing issues and the socio-cultural disruption - on both places - may not occur.

Hence sufficient water will be available in all the places. It helps to expand the farming area. Simultaneously during construction and maintenance of this pipeline system, more number of less educated and illiterate people may get employment.

\section{[B] Usage of Pipe Line System When Floods Occur Due to Heavy Rain in Urban Areas}

When it rains heavily, the streets in the Towns / Cities will become waterlogged due to surface runoff. This water can also be transferred through the pipeline system and stored in artificial dry lakes.

Every Town / City / Metro cities should maintain at least four giant size dry lakes to collect the rain water 
flooded in its streets. It is the responsibility of the Administration of the Towns / Cities to keep the lakes dry (Without any water storage) and ready to collect the heavy rain waters coming from its streets through pipe lines.

Hence the urban people can continue their day to day activities even it rains heavily for many days. The same system may also be implemented in rural areas.

Coastal Cities / Towns may transfer the rain water to sea through pipe lines. Hence they need not maintain the dry lakes.

\subsection{Drought and Pipe Line System}

To overcome the drought related issues, GIANT SIZE Dams / Water storage units have to be constructed on Both Sides of the river mouth of all rivers. Before confluence to the sea, river water is to be collected on both side Dams. From there, water should be transferred to the ponds and lakes of all the places through pipe lines.

Hence by this method we can overcome the Drought related problems like Crop damages, Mass migration of people due to scarcity of water etc.,

\subsection{Water Transportation and Pipe Line System}

Excess flood water / Sea water can be transferred through pipelines to man-made canals for water transportation. Canals are to be constructed with maximum level of Depth and Width. These canals can also be utilized for Inland navigation.

\subsection{Water Transfer Through Sea and Pipe-Line System}

The fresh water from river mouth can be transferred to other land areas by this Tangential line method. Here also the submerged pipe line (Flexible pipes) in the sea water should be paralleled to the imaginary tangential line of the Earth. For that we may utilize the air balloons to hold the pipe line accordingly.

\section{Boon}

This chain system will be a boon to the world which could save the invaluable lives from flood related problems.

It also helps government to overcome the devastation caused by flood like

1. The spread of water borne diseases.

2. River bank erosion, wiping away of assets, Infrastructural damage, landslides etc.,

3. Cost in Arranging Relief Camps, Delivery of flood packets through helicopters etc.,

4. Huge funds \& Time required to overcome the economic damages caused by flood etc.,

5. Psychological Problems faced by the affected people which in turn affect the Normalcy to the core

By implementing this method our Globe could see substantial improvements for its inhabitants and for the future management of water issues. Altogether by addressing these challenges, more water would be available to cater more people, a more constant supply to those who already have access to water, and a more secure tomorrow even despite prospects of heavier monsoons in the future. With the use of this method, the change can happen faster and cheaper. All of us have to take individual responsibility to save every drop of water for the sake of our next generations. This also could stop the sucking of water from the underground with undue respect to the nature where we live which we could prevalently see through out the world.

Throughout the history, man had developed his capacity to collect and store water. There is no technology available with human kind that is capable of increasing the availability of this natural resource and only possibility is to conserve it. This method of continual transferring water through pipe lines and storing water in much number of tanks and lakes will increase the quantity of water in the world which is now being drained into sea with out any use. Because of this Distribution of water to many parts across the world, naturally, the cropping area will be increased. And more number of trees will be planted.

\section{Discussion: Advantages and Benefits}

1. Drinking water problem will be solved permanently.

2. No electricity is required.

3. This is one time job.

4. More land can be utilized for Agriculture.

5. Flood water will be drained immediately from flood hit area to far away place. 
By proper planning and implementing, we can identify the lower lever areas

[which are frequently affected by floods] and set the pipelines before the flood season. For this purpose we may utilize our satellites.

6. We may fix the pipes on the bank of the rivers to transfer the overflowing excess water. So, flood related tragedies might be reduced.

7. Displacement of people for the sake of project may not arise.

8. Water can also be transferred from the river mouth to the land areas.

9. The slob side of the hills and mountain ranges can be utilized to fix the pipes.

10. The success of the project could be extended to the process of transferring and utilizing the sea water for the purpose of cleaning drainage and for canal transportation in main land.

11.The fire problems of the dense forest can also be solved.

12.It might provide big job opportunity to the unemployed people.

\section{Results}

Thus, we may transfer the water from unwanted areas to the needy places through this system for the benefit of the flora and fauna of the Globe.

\section{Copyrights}

Copyright for this article is retained by the author(s), with first publication rights granted to the journal.

This is an open-access article distributed under the terms and conditions of the Creative Commons Attribution license (http://creativecommons.org/licenses/by/4.0/). 